\title{
A cross sectional study on primary immunization coverage of children between the age group of 12-36 months under the national immunization programme in rural field practice area of Shimoga institute of medical sciences, Shimoga, Karnataka, India
}

\author{
Raghavendraswamy Koppad*, Santosh Kumar A., Chandrashekar S. V., Dhananjay K. S.
}

Department of Community Medicine Shimoga Institute of Medical Sciences (SIMS), Shivamogga, Karnataka, India

Received: 14 April 2016

Accepted: 02 May 2016

\section{*Correspondence:}

Dr. Raghavendraswamy Koppad,

E-mail: rrk6633@gmail.com

Copyright: (C) the author(s), publisher and licensee Medip Academy. This is an open-access article distributed under the terms of the Creative Commons Attribution Non-Commercial License, which permits unrestricted non-commercial use, distribution, and reproduction in any medium, provided the original work is properly cited.

\section{ABSTRACT}

Background: Immunization is the process whereby a person is made immune or resistant to an infectious disease, typically by the administration of a vaccine. Vaccines stimulate the body's own immune system to protect the person against subsequent infection or disease. Immunization is a proven tool for controlling and eliminating life-threatening infectious diseases and is estimated to avert between 2 and 3 million deaths each year. So it is essential to have $100 \%$ immunization coverage and to improve the knowledge of parents about vaccines and immunization.

Methodology: Across-sectional study was conducted in the Ayanuru rural field practice area of SIMS, Shimoga, during the months of March 2016 for one month. Children within the age group 12-36months were included as the study subjects. 30 Cluster sampling was used. Sample size was 240 (8 clusters*30). Evaluation form given in the Universal Immunization Programme (UIP) was used as the questionnaire. Data was analyzed with the help of XL spread sheet and results are presented in proportions and percentages.

Results: Among the 240 informants/guardians, all were mothers of participated children. Around $43.3 \%$ of the informant's had studied till High school and around 10\% were illiterate. Among the participants $41 \%$ were belonged to the class-IV socio-economic status. Vaccination coverage was at acceptable level for all the primary vaccines. Over all $98 \%$ of the children were fully immunized. It has been observed that $100 \%$ of coverage has been achieved for all the live vaccines (BCG, OPV, Measles) at all sub-centers of our field practice area. But in case of killed vaccine (pentavalent) coverage was less i.e. 92\%. Only 23\% of informants had knowledge about the BCG vaccination. When asked for the schedule of immunization, only $37.5 \%$ of the people could correctly recall. Only $20.5 \%$ of study population (parents/guardian) had knowledge about pentavalent and OPV vaccines; while half (48.5\%) of the people had better awareness about measles vaccine.

Conclusions: Overall, coverage of immunisation (98\%) was at appreciation level in the study area. Good coverage has been established for BCG, OPV and measles. Pentavalent vaccine, the commonest vaccine missed due to lack of awareness about the disease. Even though the coverage is better awareness regarding disease covered under Universal Immunisation programme and their vaccines is very poor in the study area, which needs to be addressed soon. Coverage of pentavalent vaccine can be improved by effective community mobilization by ASHAs (Accredited Social Health activist) and using mobile phone based SMS reminders of due dates.

Keywords: BCG, Pentavalent, UIP, Immunisation 


\section{INTRODUCTION}

Immunization is the process whereby a person is made immune or resistant to an infectious disease, typically by the administration of a vaccine. ${ }^{1}$ Vaccines stimulate the body's own immune system to protect the person against subsequent infection or disease. Immunization is a proven tool for controlling and eliminating life-threatening infectious diseases and is estimated to avert between 2 and 3 million deaths each year. ${ }^{2}$ It is one of the most costeffective health investments, with proven strategies that make it accessible to even the most hard-to-reach and vulnerable populations.1 Recent estimates suggest that approximately 34 million children are not completely immunized with almost 98 percent of them residing in developing countries. ${ }^{3}$ In 1985, the Universal Immunization Programme was started in India with the intention of covering $85 \%$ of the target infants with the vaccines against six most dangerous and life threatening infections by 1990 . Unfortunately we have not achieved this target yet. Vaccines included were BCG, 3 doses of DPT \& OPV and measles. ${ }^{4}$ Vaccination coverage in India is far from complete despite the longstanding commitment to universal coverage. ${ }^{5}$ According NFHS-3 (National Family Health Survey-3) only $44 \%$ of the children between the age group 1-2 years have received basic immunization package. It is very essential to reach $100 \%$ Immunisation coverage to reduce the burden of Infant and under five mortality rates (child survival, Millennium development Goal-5) of the country, which is currently very high. ${ }^{6}$

With this back ground we undertook a cross sectional study on level of primary immunization coverage among children of 12-36 months and awareness regarding vaccines covered under National Immunization programme, among parents or guardians of above children, in rural field practice area of SIMS, Shimoga.

Objectives of the study is to assess the primary immunization coverage of children between the age group of 12-36 months in rural area and to assess the awareness about immunization schedule and vaccines covered in Universal Immunization Programme (UIP) among parents or guardians of the children.

\section{METHODS}

Across-sectional study was conducted in the Ayanuru rural field practice area of SIMS, Shimoga, during the months of March 2016 for one month. Children within the age group 12-36 months were included as the study subjects. Only children who were permanent residents of the area were included in the study (who is residing in the place from last 6 months). Either of the parents or guardian of the child was the key informant. There are four sub centers (SCs) in Aynur CHC, two Anganawadis (AWs) from each SCs were included in the study as the clusters (30 cluster sampling was used). So the total clusters were eight. From each cluster 30 children were selected randomly with the help of anganawadi register. So, the sample size was 240. Evaluation form given in the Universal Immunization Programme (UIP) was used as the questionnaire (after modified to suit the local condition) for the survey. Information was collected on socio demographic factors, primary immunization of child and awareness regarding Universal Immunization schedule and individual vaccines. Data was analyzed with the help of XL spread sheet and results are presented in proportions and percentages. Informed consent was taken from all the informants before collecting data; permission for the study was taken from respective higher authority. Ethical clearance was obtained from institutional ethical committee (Annexure-1).

\section{RESULTS}

Table 1: Distribution of participants according place (sub-centres).

\begin{tabular}{|l|l|}
\hline Places & Number \\
\hline Aynur & 60 \\
\hline Sirigere & 60 \\
\hline Thammadihalli & 60 \\
\hline Benavalli & 60 \\
\hline Total & 240 \\
\hline
\end{tabular}

Table 2: Distribution of informants according to age.

\begin{tabular}{|lll|}
\hline Age Groups & Number & Percentage \\
\hline$<20$ & 8 & $3.3 \%$ \\
\hline $21-25$ & 168 & $70.2 \%$ \\
\hline $26-30$ & 43 & $18 \%$ \\
\hline$>30$ & 21 & $8.5 \%$ \\
\hline Total & 240 & $100 \%$ \\
\hline
\end{tabular}

Table 3: Distribution of informants according education status.

\begin{tabular}{|lll|}
\hline Education & Number & Percentage \\
\hline Illiterate & 22 & $9.1 \%$ \\
\hline Primary & 12 & $5 \%$ \\
\hline Higher Primary & 53 & $22 \%$ \\
\hline High- School & 104 & $43.3 \%$ \\
\hline PUC & 38 & $15.8 \%$ \\
\hline Degree & 11 & $4.5 \%$ \\
\hline Total & 240 & $100 \%$ \\
\hline
\end{tabular}

Among the 240 informants/guardians (Table 1), all were mothers of participated children. Maximum informants belonged to the age group of 21 to $25(70.2 \%)$ and the least number of people belonged to the age group of less than $20(3.3 \%) .18 \%$ and $8.5 \% \%$ of the sample population belonged to the age group of 26 to 30 and more than 30 respectively (Table 2). From our studies it was gathered that maximum i.e. $43.3 \%$ of the informant's had studied till High school and around $10 \%$ were illiterate (Table 3). All the participants belonged to either 
Hindu religion or Islam while Hindus made a majority with $88 \%$, Muslims occupied a minority of $12 \%$ (Figure $1)$.

Among the participants $41 \%$ were belonged to the classIV socio-economic status; while $25 \%$ and $20 \%$ belonged to the class-III and class-II respectively (Table 4).

Table 4: Distribution of participants according to socio-economic status.

\begin{tabular}{|lll|}
\hline Socio-economic Status & Number & Percentage \\
\hline Class-1 & 31 & $13 \%$ \\
\hline Class-2 & 48 & $20 \%$ \\
\hline Class-3 & 60 & $25 \%$ \\
\hline Class-4 & 101 & $41 \%$ \\
\hline Total & 240 & $100 \%$ \\
\hline
\end{tabular}

Table 5: Percentage of immunization coverage in various rural field practice areas of SIMS, Shimoga.

\begin{tabular}{|lllll|}
\hline Area & $\begin{array}{l}\text { Bcg } \\
(\%)\end{array}$ & $\begin{array}{l}\text { Opv } \\
(\%)\end{array}$ & $\begin{array}{l}\text { Pentavalent } \\
(\%)\end{array}$ & $\begin{array}{l}\text { Measles } \\
(\%)\end{array}$ \\
\hline Ayanur & $\begin{array}{l}60 \\
(100 \%)\end{array}$ & $\begin{array}{l}60 \\
(100 \%)\end{array}$ & $\begin{array}{l}56 \\
(93 \%)\end{array}$ & $\begin{array}{l}60 \\
(100 \%)\end{array}$ \\
\hline Sirigere & 60 & 60 & 57 & 60 \\
& $(100 \%)$ & $(100 \%)$ & $(93.1 \%)$ & $(100 \%)$ \\
\hline $\begin{array}{l}\text { Thambadi } \\
\text { halli }\end{array}$ & 60 & 60 & 54 & 60 \\
\hline Benuvalli & 60 & 60 & 55 & $(100 \%)$ \\
\hline $\begin{array}{l}\text { Total } \\
\text { coverage }\end{array}$ & $\begin{array}{l}(100 \%) \\
(100 \%)\end{array}$ & $\begin{array}{l}(100 \%) \\
(100 \%)\end{array}$ & $(92 \%)$ & $(100 \%)$ \\
\hline
\end{tabular}

Table 6: Knowledge about tuberculosis and BCG Vaccine.

\begin{tabular}{|lll|}
\hline Places & Vaccine for TB & $\begin{array}{l}\text { Knowledge about } \\
\text { TB }\end{array}$ \\
\hline Aynur & $6(9 \%)$ & $36(59 \%)$ \\
\hline Sirigere & $21(34 \%)$ & $37(62 \%)$ \\
\hline Thammadihalli & $19(31 \%)$ & $30(50 \%)$ \\
\hline Benavalli & $10(16 \%)$ & $24(40 \%)$ \\
\hline Total & $56(23 \%)$ & $127(53 \%)$ \\
\hline
\end{tabular}

Vaccination coverage was at acceptable level for all the primary vaccines. Over all $98 \%$ of the children were fully immunized. It has been observed that $100 \%$ of coverage has been achieved for all the live vaccines (BCG, OPV, Measles) at all sub-centers of our field practice area. But in case of killed vaccine (pentavalent) coverage was less i.e. $92 \%$. It was observed that pentavalent vaccination was $100 \%$ and $98 \%$ for first and second doses respectively, the same was dropped down to around $80 \%$ for third dose. Under coverage of the third dose was the reason for lesser coverage of pentavalent vaccine in the study area. Significant amount of under coverage was found in thammadihalli and benuvalli areas compared to other 2 sub-centres (Table 5).

Table 7: Awareness regarding measles and pentavalent vaccines.

\begin{tabular}{|lll|}
\hline Places & $\begin{array}{l}\text { Time of measles } \\
\text { vaccine }\end{array}$ & $\begin{array}{l}\text { Knowledge } \\
\text { about } \\
\text { Pentavalent and } \\
\text { OPV }\end{array}$ \\
\hline Aynur & $23(39 \%)$ & $10(16 \%)$ \\
\hline Sirigere & $29(48 \%)$ & $12(20 \%)$ \\
\hline Thammadihalli & $28(46 \%)$ & $6(9 \%)$ \\
\hline Benavalli & $37(56 \%)$ & $22(32 \%)$ \\
\hline Total & $117(48.5 \%)$ & $50(20.5 \%)$ \\
\hline
\end{tabular}

Only $23 \%$ of informants had knowledge about the BCG vaccination, over $3 / 4^{\text {th }}$ of the remaining informants took the BCG vaccination blindly. Nearly half $(47 \%)$ of the informants didn't have knowledge about tuberculosis. (Table 6).

We observed that good proportion of (91\%) study informants were correctly told the day of immunization. When asked for the schedule of immunization, only $37.5 \%$ of the people could correctly recall. Consciousness of the number of visits (four) to the immunization center in the first year of life was found to be only $41.8 \%$ (Figure 2).

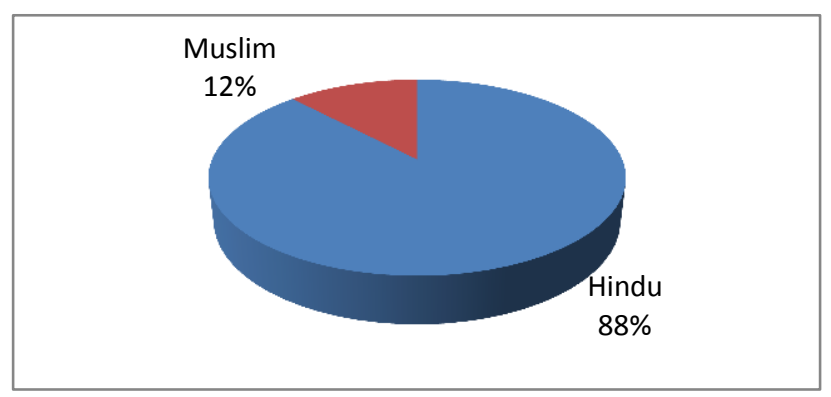

Figure: 1 Distribution of informants according to religion.

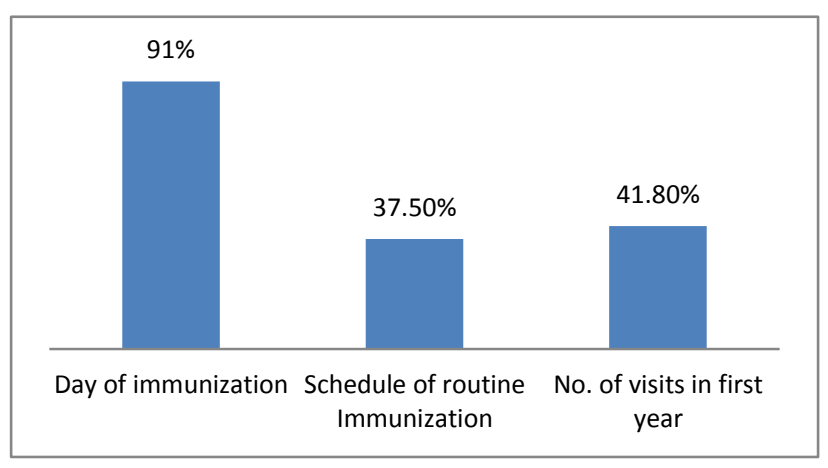

Figure 2: Knowledge about day of immunization, age of routine immunization and visits in first year. 


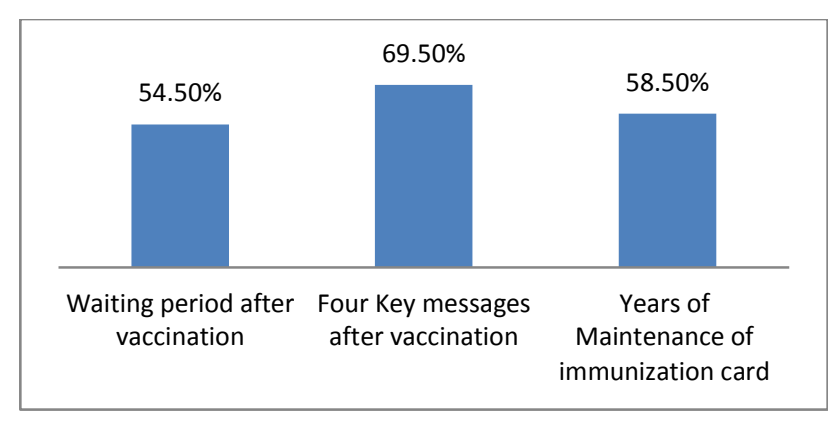

Figure 3: Knowledge about post vaccination waiting period, four key messages and immunization card.

From the Table 7 , it can be concluded that only $20.5 \%$ of study population (parents/guardian) had knowledge about pentavalent and OPV vaccines; while around half $(48.5 \%)$ of the people had better awareness about measles vaccine.

Over all awareness about the waiting period of vaccination was $54.5 \%$ in study area. The (Figure 3 ) only around $70 \%$ of people could recall all the four key messages which were given after each vaccination. Still more than $1 / 3^{\text {rd }}$ of the people didn't know the importance of maintaining the immunization card.

\section{DISCUSSION}

In the present study 240 children were participated from four sub centres and eight clusters. In all the children mothers were the key informants. Maximum numbers of mothers were belonged to the age group of 21-25 Years $(70.2 \%)$ and only $3.3 \%$ of the mothers (informants) were belonged to the age group of less than or Equal to 20 years, indicating very less chances of teenage pregnancy. A study conducted by Munda NK in Ranchi reported that mean age of mothers/informants participated in similar study was 25 years. ${ }^{5}$ In our study we have observed that over $90 \%$ of the mothers were literate. Contrast to our finding, various Studies conducted across the country have shown that the literacy rate among the mothers in rural areas varies from 34.7 percent to 60 percent. ${ }^{5,7}$ All the participants belonged to either Hindu religion or Islam while Hindus made a majority with $88 \%$, Muslims occupied a minority of $12 \%$. Almost all (98\%) the children were fully immunized. It has been observed that $100 \%$ of coverage has been achieved for all the live vaccines (BCG, OPV, Measles). But in case of killed vaccine (pentavalent) coverage was comparatively less (92\%). The coverage was almost $100 \%$ for the first 2 doses of pentavalent vaccine, but the same was $80 \%$ for the $3^{\text {rd }}$ dose. According to National Family Health survey-3 in rural area, the vaccination coverage for the DPT, which is a part of pentavalent vaccine was $72 \%{ }^{6}$ According to Ministery of Health family welfare the coverage of various vaccines under UIP are $86.9 \%$, $70.4 \%, 71.5 \%$ and $74.1 \%$ respectively for $\mathrm{BCG}$, OPV, DPT (Part of pentavalent) and measles respectively. ${ }^{8} \mathrm{We}$ found that only $47 \%$ and $23 \%$ of the mothers had knowledge about tuberculosis and the BCG vaccine respectively. While in the study conducted by Kapoor Rachana et al reported that $52.5 \%$ and $30.2 \%$ of the respondents knew about tuberculosis and BCG vaccine respectively. ${ }^{9}$ In our study only $20.5 \%$ of study population (parents/guardian) had knowledge about pentavalent and OPV vaccines; while only near half $(48.5 \%)$ of the people had awareness about measles vaccine. In a similar study KAP study done by Shamila Hamid in North Kashmir (2011), about "Immunization of children in a Rural Area, India: A KAP study" revealed that $39 \%$ of the mothers knew about OPV; $20 \%$ knew about DPT (part of pentavalent vaccine) and $32 \%$ of the mothers had fare knowledge about measles. ${ }^{10}$ In the present study around $70 \%$ of the study subject had the knowledge about 4 key messages which were given to them after the vaccination like. ${ }^{1}$ What vaccine was given and what disease it prevents. ${ }^{2}$ When to come for the next visit. $^{3}$ What are the minor side-effects and how to deal with them. ${ }^{4}$ To keep the vaccination card safe and to bring it along for the next visit. $58.5 \%$ of people in our study knew that immunization card should be kept safe till child attains 16 years of age. ${ }^{11}$

\section{CONCLUSION}

Overall, coverage of immunisation (98\%) was at appreciation level in the study area. Good coverage has been established for BCG, OPV and measles due to conventional immunization at birth and comparatively better awareness among people. Pentavalent vaccine, the commonest vaccine missed due to lack of awareness about the disease, especially the third dose of pentavalent .Even though the coverage is better awareness regarding disease covered under Universal Immunisation programme and their vaccines is very poor in the study area, which needs to be addressed soon. Coverage of pentavalent vaccine can be improved by effective community mobilization by ASHAs (Acredited Social Health activist) and using mobile phone based SMS reminders of due dates. Health education part should be given more emphasis during immunization sessions and in under five clinics regarding immunization schedule and vaccines covered in it. Effective utilization of Information Education Communication (IEC) materials of immunization programme. Effective conduction of monthly Village Health and Nutrition days and to give more emphasis to maternal and child health topics especially immunization related aspects, targeting poor, mothers and mothers having lowered level of education and illiterate.

\section{ACKNOWLEDGEMENTS}

At the outset, I would like to acknowledge with gratefulness the contribution of medical officer of ayanuru primary health care. The people in the community without whose support the study wouldn't have been possible. 
Funding: No funding sources

Conflict of interest: None declared

Ethical approval: The study was approved by the Institutional Ethics Committee

\section{REFERENCES}

1. World Health organization. Immunisation. Vaccine preventable diseases. Cited 2016 February 24. Available http://www.who.int/topics/immunization/en/. Accessed on 20 March, 2016.

2. Park K. Textbook of Preventive \& Social Medicine. $22^{\text {nd }}$ ed. Jabalpur: Banarsidas Banot; 2014.

3. Dubey DK, Singh S, Kushwah SS. A study on utilisation of immunisation services by slum dwellers of municipal corporation area of Rewa city in Madhya Pradesh. Indian J Comm Health. 2013;25:110-5.

4. Punith K, Lalitha K, Suman G, Pradeep BS, Jayanth Kumar K. Evaluation of primary immunisation coverage of infants under universal immunisation programme in an urban area of Bangalore city using cluster sampling and lot quality assurance sampling techniques. Indian J Community Med. 2008;33:151.

5. Munda NK, Sagar V, Kashyap V, Kumar M. Study on immunization status among children's between 2 to 6 years of age group in rural field practices area of Ormanjhi of RIMS, Ranchi. JDMS. 2016;15:10812.
6. National Family Health Survey 3 (NFHS-III) 2007. Department of Health \& Family Welfare, Govt. Of India. International Institute of Population Sciences, Mumbai.

7. International Institute for Population Sciences (IIPS), Indian Institute of Health Management Research (IIHMR), Jaipur. Reproductive and Child Health District Level Household Survey (Dlhs-4), Karnataka, 2012-13.

8. Universal Immunization Program. Immunization Division at MoHFW. Available at: http://www.mohfw.nic.in/WriteReadData/1892s/Im munization_UIP.pdf. Accessed on 28 February 2016.

9. Kapoor R, Vyas S. Awareness and knowledge of mothers of under-five children regarding immunization in Ahmedabad. Healthline. 2010;1(1):12-5.

10. Mereena, Sujatha R. A study on knowledge and attitude regarding vaccines among mothers of under five children attending pediatric OPD in a selected hospital at Mangalore. JNHS. 2014;3:39-46.

11. Immunization Handbook for Medical officers. Department of Health \& Family Welfare, Govt. Of India. 2008.

Cite this article as: Koppad R, Kumar AS, Chandrashekar SV, Dhananjay KS. A cross sectional study on primary immunization coverage of children between the age group of 12-36 months under the national immunization programme in rural field practice area of Shimoga institute of medical sciences, Shimoga, Karnataka, India. Int J Community Med Public Health 2016;3:1310-4. 